\title{
単一板ばね支点の変形
}

\author{
理論 (第 1 近似) \\ 西山卓*.増, 尾龍 一*.前田親 良*・村岡茂 信*
}

\section{A Theoretical Analysis on Deformation of Fulcrum of a Single Flat Spring Used in Scale}

Taku Nishiyama*, Ryuichi Masuo*, Chikayoshi Maeda* and Shigenobu Muraoka*

Deformation of a single flat spring in a fulcrum is analyzed. Two fundamental differential equations are solved using the first order approximation in the angle $\theta$ between a tangent at an arbitrary point $P$ on the spring and a vertical line.

It is found that the problems on the deformation of the single flat spring can be evaluated algebraically using only the addition theorem for hyperbolic functions, and that the deformation curve of the flat spring is expressed by a part of hyperbolic or exponential curve.

Application of the fulcrum of a single flat spring to a scale is presented in comparison with the knife-edge fulcrum.

\section{1. まえがき}

はかりに用いられる板ばね支点は，支点位置の再現 性が良く，機械加工した部品を組み立てるだけでかな りの精度のあのが期待できるので大量生産に適し, 各 種の分野のはかりに利用されている ${ }^{1), 2)}$. 実用されて いる支点には，いくつかの種類 ${ }^{3)}$ があるが，ての論文 で取上げた単一板ばね支点は，取付金具の構造が簡 単で経済性にすぐれ，無理な変形を起てさないので, 実用度の最す高い板ばね支点である.しかしながら， 従来は, 板ばねの変形についての解明が不十分であっ たので，主として零位法に限定して使用されてお り4)，偏位法によるはかりにすての支点を活用するに は, その変形について解明するてとを必要としてい た.

この論文は，てての傾き角が小さい場合の単一板ば ね支点の変形を解析したあのである，まず, 基本の微 分方程式を無次元化し，板ばねの法線の傾き $\theta$ につい

$\dagger$ 第 22 回応用物理学関係連合講演会で発表 (昭 50.4 ) 第 7 回計測制御に関する北海道研究集会で発表（昭 49 . 12)

* 大阪工業大学 大阪市旦区大宮 5-16-1

* Osaka Institute of Technology, Osaka (Received May 30, 1975)
て $\sin \theta$ を $\theta$ 之近似し, 微分方程式の一般解を求め た. その結果, 変形についての必要な值は, 双曲線関 数の加法定理を用いるだけで, 代数的に容易に求めら れるてとがわかった. $\sin \theta$ について， $\theta$ のもっと高 次の項まで計算を行えば，てての傾き角があっと大き い場合についても求まるが，てれらは，別報告する つありである.

解析結果の応用例として，はかりの支点や重点に用 いた場合の具体的な計算例を，ナイフエッジ支点との 対比によって示し, ナイフエッジの刃先の曲率中心に 相当する位置やてとの回転中心，四すみの誤差などが 明らかとなった。

\section{2. 理 論}

\section{1 基礎方程式}

Fig. 1 (a) 亿示すように曲げ剛性 $E I$, 長さ $l$ の板 ばねの上端 $\mathrm{A}$ を, 角 $\varphi$ 傾けて固定し，下端 B 亿荷重 $W$ ，曲げモーメント $M_{B}=x_{\mathrm{B}} W$ をかけた状態を考 える.

板ばね上の任意の点 $\mathrm{P}$ に扣ける法線の傾きを $\theta$ ，そ の曲率半径を $\rho$, 荷重 $W$ の作用線之 $\mathrm{P}$ 点の距離を $x, \mathrm{~B}$ 点から $\mathrm{P}$ 点までの板ばねの長さを $l^{\prime}$ とし, 符 号は, Fig. 1 に示すむのをすべて正にとる.すなお ち, $x_{\mathrm{A}}, x_{\mathrm{B}}, x$ は, 荷重の作用点 $\mathrm{D}$ を通る鉛直線の右 側汇あるすのを正，板ばねの法線の傾き $\varphi, \phi, \theta$ は, その法線が右下りのときを正と約束する.すると簡単 な幾何学的考察と Euler-Bernoulli の定理 $x W=$ EI/ からつぎの関係が得られる.

$$
\begin{aligned}
& d l^{\prime}=\rho d \theta=\frac{E I}{x W} d \theta \\
& d x=\rho d \theta \sin \theta=\frac{E I}{x W} d \theta \sin \theta
\end{aligned}
$$

ことで, 長さの次元をむつ量 $\lambda$ を

$$
\lambda=\sqrt{E I / W}
$$

と定義し, 本論文中では, 長さの次元をすつ量をすべ てての入で割って無次元化し，その無次元量をあとの 


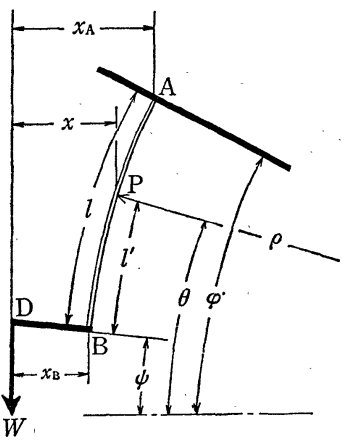

(a)

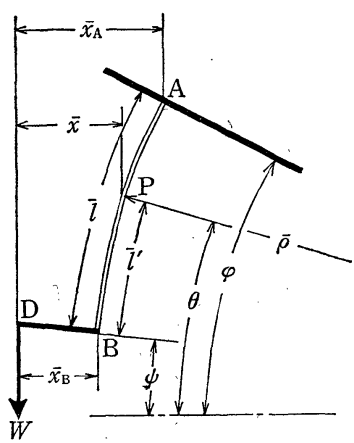

(b)
Fig. 1 Detailed representation for fulcrum of single flat spring and relation between notations and nondimensional notations

量に一を付して表わすととにする.すなわち， $x=\bar{x} \lambda$ $l=\bar{l} \lambda$ のごとくである. Fig. 1 (b) は，乙の無次元量 で表わしてあり，（1)，（2）式をこれにより書きかえ るとつぎのようになる.

$$
\begin{aligned}
& d \bar{l}^{\prime}=d \theta / \bar{x} \\
& \bar{x} d \bar{x}=\sin \theta d \theta
\end{aligned}
$$

この二つの式が，板ばねの変形を考える基礎方程式で ある。

\section{2 近似解}

上述の基礎方程式を一般的に解くことは別報にゆず ると亡とし，乙こでは， $\theta$ が小さいとして, $\sin \theta$ を $\theta$ と近似して解く. 本論文では, 以下すべてとの近似 のむとに議論を進める。とのとき, $(2)^{\prime}$ 式は, $\bar{x} d \bar{x}$ $=\theta d \theta$ となり，その解は，

$$
\bar{x}^{2}-\theta^{2}=C
$$

となる，とこに，C は積分定数で， $C$ の正， 負, 零により，(1)'式の解を三つに分類でき る.

まず，C>0 の場合について述べる. $C=c^{2}$ とおくと, (4)式は,

$$
\left(\frac{\bar{x}}{c}\right)^{2}-\left(\frac{\theta}{c}\right)^{2}=1
$$

となるから

$$
\theta=c \sinh m \quad(\bar{x}=c \cosh m)
$$

により， $m$ を定義することができる．この $m$ を $\mathrm{P}$ 点の偏角と呼ふとととする. $d \theta=c \cosh m d m$ であるから，乙れを $(1)^{\prime}$ 式に代入すると，

$$
d \vec{l}=d m
$$

が得られる．乙れは容易に積分でき，A点にお ける偏角を $m_{\mathrm{A}}, \mathrm{B}$ 点のそれを $m_{\mathrm{B}}$ とすると， $m_{\mathrm{A}}$ と $m_{\mathrm{B}}$ の関係は,

$$
m_{\mathrm{A}}=m_{\mathrm{B}}+\bar{l}
$$

となる. この基礎方程式の解を用いて具体的に， $\varphi$ $\phi, \bar{x}_{\mathrm{A}}, \bar{x}_{\mathrm{B}}$ の間の関係を求めておく.（5)，(7)式 より, $\varphi$ は次式のようになる.

$$
\varphi=c \sinh m_{\mathrm{A}}=c \sinh \left(m_{\mathrm{B}}+\bar{l}\right)
$$

ここで双曲線関数の加法定理を使って右辺を展開す ると,

$\varphi=c \sinh m_{\mathrm{B}} \cosh \bar{l}+c \cosh m_{\mathrm{B}} \sinh \bar{l}$

となり，(5)式を使えば,

$\varphi=\psi \cosh \bar{l}+\bar{x}_{\mathrm{B}} \sinh \bar{l}$

となる.同様にして，

$$
\begin{aligned}
& \psi=\varphi \cosh \bar{l}-\bar{x}_{\mathrm{A}} \sinh \bar{l} \\
& \bar{x}_{\mathrm{A}}=\bar{x}_{\mathrm{B}} \cosh \bar{l}+\phi \sinh \bar{l} \\
& \bar{x}_{\mathrm{B}}=\bar{x}_{\mathrm{A}^{\prime}} \cosh \bar{l}-\varphi \sinh \bar{l}
\end{aligned}
$$

が得られる.

つぎに，C<0 の場合については，C=- $c^{2}$ 之おき，

$$
\bar{x}=c \sinh m(\theta=c \cosh m)
$$

により， $m$ を定義すると，上述と同様にして， $m_{\mathrm{A}}$ と $m_{\mathrm{B}}$ に関する式は，(7)式と同じになり， $\varphi, \phi, \bar{x}_{\mathrm{A}}, \bar{x}_{\mathrm{B}}$ の間の関係も $(\mathrm{I}) \sim(\mathrm{IV})$ 式に示したものとまったく同 じとなる.

また，C=0 のときは， $\bar{x}=\theta$ であるから，てのと きは， $m$ を定義するまですなく，(1)'式より，

$$
\bar{l}^{\prime}=\ln \frac{\bar{x}}{\bar{x}_{\mathrm{B}}}\left(\bar{x}=\bar{x}_{\mathrm{B}} e^{l^{\prime}}\right)
$$

となる：とれより，

$$
\bar{x}_{\mathrm{A}}=\bar{x}_{\mathrm{B}} e^{l}\left(\varphi=\phi e^{l}\right)
$$

となり，とれは，(I)〜(IV)式で, $\bar{x}_{\mathrm{A}}=\varphi, \bar{x}_{\mathrm{B}}=\psi$ と したときに得られる結果と同じである. したがって， ( I )〜 (IV)式は, $\boldsymbol{C}$ の值によらず常に成立する。



(b)



(c)

Fig. 2 Typical curves of single flat spring, (a) $\psi>0$, (b) $\psi<0$ and calculated curves (c) expressed by $\bar{x}=c \cosh \bar{y}$ 




(b)

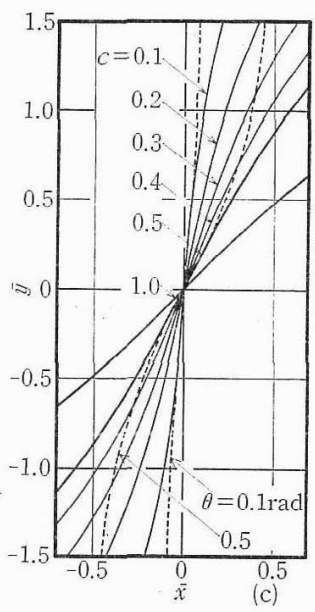

Fig. 3 Typical curves of single flat spring, (a) $\bar{x}_{B}>0$, (b) $\bar{x}_{B}$ $<0$, and calculated curves (c) expressed by $\bar{x}=c \sinh \bar{y}$

$\bar{x}=c \sinh \bar{y}$

の曲線の一部分となる (Fig。3 (a), (b) 参照). また，C=0 の場合，Fig. 4 (a) に示すよう に座標をとると，(11)式より，その形状は，

$$
\bar{x}=\bar{x} \mathrm{~B} e \bar{y}
$$

の曲線の一部分となる。

Fig. 2 (c), Fig. 3 (c) には, $c$ をパラメータ にとって，それぞれ $c \cosh \bar{y}, c \sinh \bar{y}$ の曲線 群を実線で，との曲線の傾き $\theta$ が $0.1 \mathrm{rad}$ $0.5 \mathrm{rad}$ になる点を破線でむすんで示した。 これより， $\cosh \bar{y}$ では $\theta<0$ となる領域が， $c \sinh \bar{y}$ では $\bar{x}<0$ となる領域があることがわ 汃る。

Fig. 4 (b) には， $\bar{x}_{\mathrm{B}}$ をパラメータにとって $\bar{x}_{\mathrm{B}} e \bar{y}$ の曲線群を上と同様に示した。

\section{4.はかりへの応用}

\section{3. 板ばねの形状}

板ばねの形状は，前述のCの值により，つぎの三 つに分類できる，C>0 の場合は，Fig.2 (a)，(b) において，荷重 $W$ の作用点 D を通る鉛直線上向き を $\bar{y}$ 軸，水平線右向きを $\bar{x}$ 軸にとり，(5)式の $m$ が 0 となる点が $\bar{x}$ 軸上にくるように原点走選心ば， $\theta$ が小さいので， $m$ が $\bar{y}$ に等しいと考えられる。し たがって，板ばねの形状は，乙の場合，

$$
\bar{x}=c \cosh \bar{y}
$$

で表わされる曲線の一部分しして与えられる。

$C<0$ の場合は， $(10)$ 式の $m$ が 0 となる点を座標 の原点にとると，板ばねの玥状は，

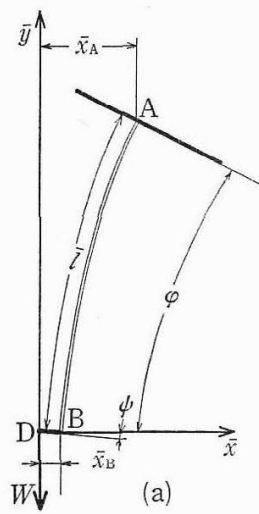

Fig. 4

(a) Typical curve of single flat spring: (b) Calculated curves expressed by $\bar{x}=\bar{x}_{B} e^{\bar{y}}$

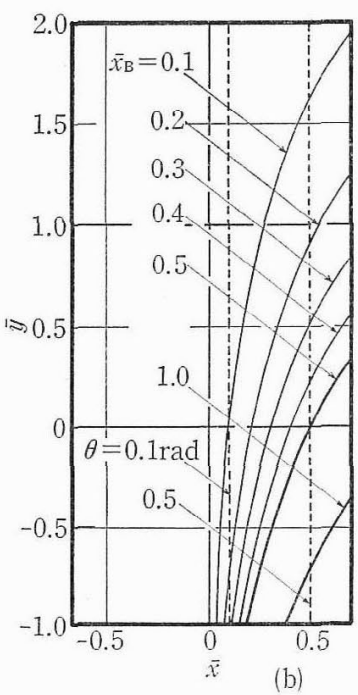

はかりに用いられるてこの支点には，取付支点 （とれを支点部と呼ふ）のほかに他のてとと連結する 裹結支点, 荷重を加究る重点(これを重点部と呼ぶ） がある。

これらに単一板ば权支点が用いられる場合，Fig.5

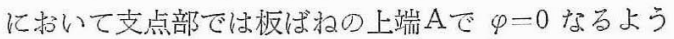
に固定され，板ばねの下端Bにてこが取付けられる. 重点部においては，A点がてとに固定され，B点に荷 重つり棒または，はかり皿が取付りられる。いまてれ らの問題を一つに过よる Fig. 5 に示すような力の かけかたをした愓合について考えると $\bar{x}_{\mathrm{B}}$ は

$$
\bar{x}_{\mathrm{B}}=\bar{a}+\bar{b} \phi
$$

となる。ここに， $\bar{a} ＼overline{b}$ はB点に取付けた剛体の力の 作用点Dに関するB点の座標である。この(16)式を用 いて $\phi$ と $\bar{x}_{\mathrm{A}}$ を $\varphi \bar{a}, \bar{b}$ で表踣之（I），(III） 式より,

Fig. 5 Fulcrum of single flat spring with load $W$ at the point $D$

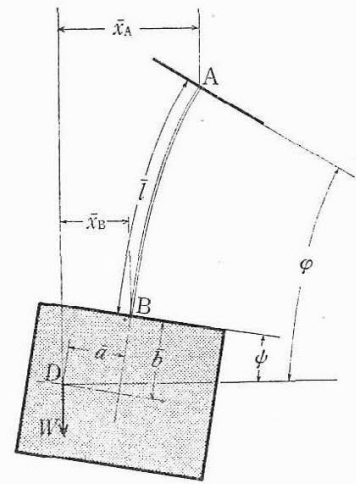




$$
\begin{aligned}
& \phi=\frac{\varphi \operatorname{cosech} \bar{l}-\bar{a}}{\operatorname{coth} \bar{l}+\bar{b}} \\
& \bar{x}_{\mathrm{A}}=\frac{(\bar{b} \operatorname{coth} \bar{l}+1) \varphi+\bar{a} \operatorname{cosech} \bar{l}}{\operatorname{coth} \bar{l}+\bar{b}}
\end{aligned}
$$

が得られる。

\section{1 ナイフエッジ支点との対比}

てての支点部，重点部にナイフエッジ支点を用いた 場合は，荷重による感度変化を防ぐために刃先の曲率 中心の軸線肪同一平面内にあるよう製作され，この平 面またはそれを代表する直線を刃線と呼えでいる。

Fig.6，Fig. 7 はてこの支点部，重点部をそれぞ れ示したあので，板ばね支点に祘ける刃線の位置を求 めるために，いずれあナイフエッ淁点の場合と単一 板ばね支点の場合を対比させて表わしてある.

まず，Fig. 6 の支点部において，ナイフエッジ支 点の刃先の曲率中心 $N$ に相当する板ば效支点の $N^{\prime}$ 点 は荷重の作用点 D通る鉛直線とB点での板ばねの接 線との交点となり， $\overline{\mathrm{BN}^{\prime}}=\bar{x}_{\mathrm{B}} /|\phi|$ だ与兄られるから （I）式より $\overline{\mathrm{BN}^{\prime}}$ は

$$
\overline{\mathrm{BN}^{\prime}}=\operatorname{coth} \bar{l}
$$

となる。またてこの回転中心 $O^{\prime}$ は，A点を通る鉊直 線とB点での板ばねの接線との交点になり $\overline{\mathrm{BO}^{\prime}}=\left(\bar{x}_{\mathrm{B}}\right.$ $\left.-\bar{x}_{\mathrm{A}}\right) /|\phi|$ で与えられ，(I)，(III)式より

$$
\overline{\mathrm{BO}}=\operatorname{coth} \bar{l}-\operatorname{cosech} \bar{l}=\tanh \frac{\bar{l}}{2}
$$

となる。

一方，ナイフエッジ支点の刃先の曲率半径テに相当 するあのが板ばね支点では $\overline{\mathrm{N}^{\prime} \mathrm{O}^{\prime}}$ にあたり，この $\overline{\mathrm{N}^{\prime} \mathrm{O}^{\prime}}$ は(19)，(20)式より

$$
\overline{\mathrm{N}^{\prime} \mathrm{O}^{\prime}}=\overline{\mathrm{BN}^{\prime}}-\overline{\mathrm{BO}^{\prime}}=\operatorname{cosech} \bar{l}
$$

となる。したがって，板ばねの長さに相当するしが 大きくなると， $\overline{N^{\prime} O^{\prime}}$ は小さくなり，乙れはナイフエ ッジ支点の場合の刃先の曲率半径 $r$ をさくしたもの に対応する。

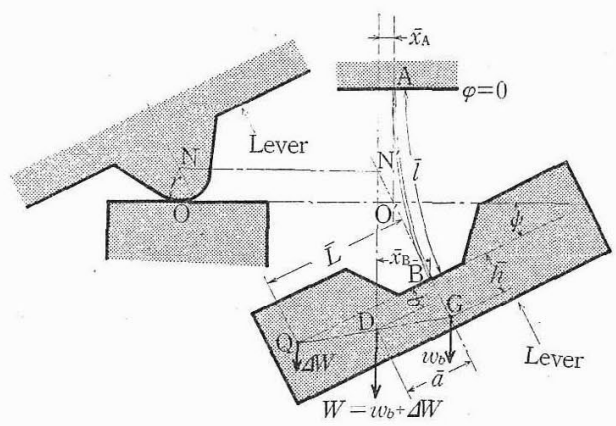

Fig. 6 Explanation of single flat spring compared with knife-edge in fulcrum pivot

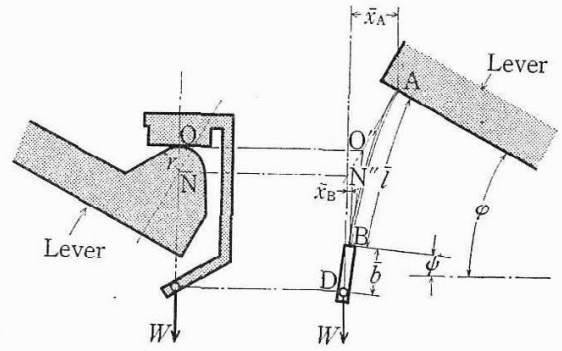

Fig. 7 Explanation of single flat spring compared with knife-edge in load pivot

つぎに Fig. 7 は $\varphi$ 傾いたてこの重点部を示した あので，つり棒の先端Dでなめらかなピン接手により 荷重をつるしてある.したがって，てのときは $\bar{a}=0$ とみなせる。てての線を決定するに必要な $\mathrm{N}^{\prime \prime}$ 点 (ナイフエッジ支点の $N$ 点に相当する) は，荷重の作 用点 Dを通る鉛直線とA点に拈ける板ばねの接線との 交点となり $\overline{\mathrm{AN}^{\prime \prime}}=\bar{x}_{\mathrm{A}} / \varphi$ で与えられるから (18)式よ b

$$
\overline{\mathrm{AN}^{\prime \prime}}=\frac{\bar{b} \operatorname{coth} \bar{l}+1}{\operatorname{coth} \bar{l}+\bar{b}}
$$

となる、また，てとから見たつり棒の回転中心 O (ナイフエッジの○点に相当する)は，A点における板 ばねの接線とB点に拉りるそれとの交点となり, $\overline{\mathrm{AO}^{\prime \prime}}$ は

$$
\overline{\mathrm{AO}^{\prime \prime}}=\frac{\bar{x}_{\mathrm{A}}-\bar{x}_{\mathrm{B}}-\bar{l} \phi}{\varphi-\phi}=\frac{\bar{b}+\operatorname{coth} \frac{\bar{l}}{2}-\frac{\bar{l}}{2} \operatorname{cosech}^{2} \frac{\bar{l}}{2}}{1+\bar{b} \operatorname{coth} \frac{\bar{l}}{2}}
$$

となる. Fig. 8 には $\overline{\mathrm{AN}^{\prime \prime}}, \overline{\mathrm{AO}^{\prime \prime}}$ を $\bar{l}$ の関数として らをパラメータにこって示してある. $\overline{\mathrm{AN}^{\prime \prime}}, \overline{\mathrm{AO}^{\prime \prime}}$ の值はいずれす さに相当するち にほとんど関係しないととがわかる。

\section{2 てこの感度について}

単一板ばね支点を用いたてこの感度について考え る.いま, Fig. 6 に示す重量

Fig. 8 Both $\overline{\mathrm{AN}^{\prime \prime}}$ and $\overline{\mathrm{AO}^{\prime \prime}}$ as a function of $\bar{l}$

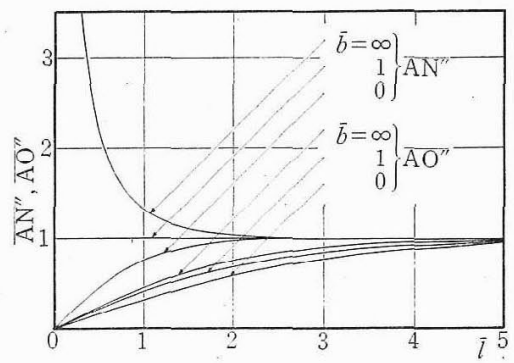


点に微小荷重 $\Delta W$ を办けるととにより，てこが $\phi$ 傾 いてつりあったとする，とこで $W=w_{0}+\Delta W$ と杼 けば, $\bar{a}, \bar{b} は$

$$
\bar{a}=\frac{\Delta W}{W} \bar{L} \quad \bar{b}=\frac{w_{b}}{W} \bar{h}
$$

となる.てこの感度 $S は|\phi| / \Delta W$ 之定義されてい る汃ら(17)式より

$$
S=\frac{|\phi|}{\Delta W}=\frac{\bar{L}}{W \operatorname{coth} \bar{l}+\omega_{b} \bar{h}}
$$

となる. (25)式の分目はてとの復元モーメントに相当 するあのを表わし，第 1 項が板ばねの䏚性によ゙るすの で，筙2 項が重力によるもので岁る。

ここで，前節の(19)式を用いて弾性による復元モー メントに相当する項を重力によるもののように位遀エ ネルギーで表わすと (25)式は

$$
S=\frac{\bar{L}}{w_{b}\left(\overline{\mathrm{B}} \overline{\overline{N^{\prime}}}+\bar{h}\right)}
$$

と書きかえるととができる。てれは，ナイフエッジ支 点を用いたてての感䧹の式とまったく同じで苟り，ナ イフエッジの妇先の曲率中心相当する $N^{\prime}$ 点汃らて この重心点Gまでの距離によって，てこの傾きによる 復元モーメントを求狈れば，板ばね支点索用いたてと の感度はナイフエッジ支点を用いたものと同じにな る.

\section{3 四すみの誤差}

はかり血老B点に固定した場合は Fig.9のように

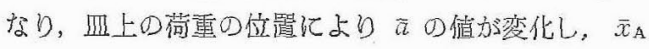
あ変化する、したがって，はかりの指示値す变化する

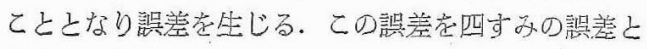
呼んでいる。

てれは(18)式の可の変化によって生じるが, $\operatorname{cosech} \bar{l}$



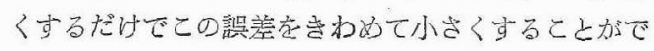
きる.

\section{5. ま と め}

単一板枝称の变佬について 基濋方程式老導き，板ばねの 法線の傾さ $\theta$ 飞ついて $\sin \theta$ 意 $\theta$ 上近似てその解を求问 つぎの絓諭を得た.

(1) 板ばねの班状は，変形 に市ずかる力のかかわ方や板 ばねの固定端の傾きによっ て，基碳方程式の解である (4)式の㔍分定数C分正空ら $c \cosh \bar{y}$ で, 負なら $c \sinh \bar{y}$ で, 零なら $\bar{x}_{B}$ ey で表わされ

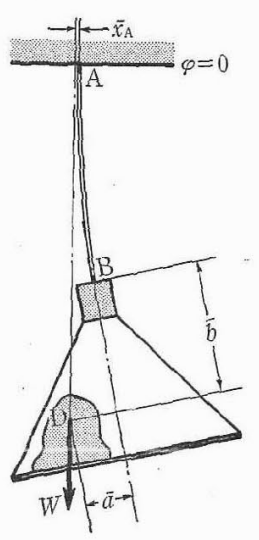

Fig. 9 Shift error る曲線群の一部分之なる。


$\bar{x}_{\mathrm{B}}$ の間の関係は，(1)の形状によらずいつです(I)〜 (IV)式で表宁される。

(3) 上記の解析結具の応用例として，はかりのてと の支点部，重点部に算一板ば、文点老使用した場合， 設計に必要なナイフェッジ支点の刃先の曲率中心に相 当する位置，回転中心，てての感度，四するの誤差を 求めた。

(4) 単一板ばね支点とナイフエッジ支点との対比 は，Fig. 6, Fig. 7 のうになる。

\section{参考文献}

1) 增尾, 前田: はかりに使われる弾性支点について, 計量 管理ジャーナル，1-2，10/16 (1968)

2) 屁晅, 明間: はかりに用いられる弾性支点, 日本機耀学 会誌, 71-591，551/555 (1968)

3) R. Masuo and C. Maeda: Performance of Elastic Fulcrum in a Beam Type Balance, ISA, Proceedings, 19, part 121 (1964)

4) 增尾, 前田: てとの蔡性支点について, 日本機械学会論 文集，26-172，1714/1719 (1960) 